\title{
USING OF MISOPROSTOL VAGINALLY PRIOR TO INTRAUTERINE CONTRACEPTIVE DEVICE INSERTION FOLLOWING PREVIOUS INSERTION FAILURE: RANDOMIZED CLINICAL TRIAL
}

\author{
By \\ Amr Mohamed El-Sayed, Mofeed Fawzy Mohamed and Samir Khamis \\ Galal
}

Department Obstetrics and Gynecology, Faculty of Medicine, Al-Azhar University

Corresponding author: Amr Mohamed Elsayed,

Mobile: (+20) 01022475504, E-mail: amr_elsayed55@gmail.com

\begin{abstract}
Background: Intrauterine devices (IUDs) are good contraceptive method for women as they have a long acting contraceptive effect compared to other hormonal methods. Misoprostol or prostaglandin El (PGE1) analogue is a synthetic prostaglandin that has been used to induce cervical ripening in vaginal delivery and in medical induction of abortion.
\end{abstract}

Objective: To investigate the possible effect of vaginal administration of misoprostol to insertion of IUCDs in women with previous IUCD insertion failure.

Subjects and methods: This study was done at Obstetrics and Gynecology Department of at El-Hussien hospital. It is a double blind randomized clinical trial. The study included 100 patients with previous failed attempt of IUD insertion, divided into two equal groups: Group I received misoprostol prior to IUD insertion and group II received placebo to IUD insertion.

Results: There was high significant difference between the two groups regarding the degree of cervical softening and its effect on the success rate of IUCD insertion in each group.

Conclusion: Vaginal misoprostol before IUD insertion in parous women with previous insertion failure increased the rate of successful insertion, particularly in women with previous cesarean delivery.

Keywords: Misoprostol, Insertion failure, intrauterine contraceptives, Copper intrauterine device, Levonorgestrel-releasing intrauterine system.

\section{INTRODUCTION}

Intrauterine devices (IUDs) are safe, reliable and highly effective forms of long-acting reversible contraception. Between 2008 and 2014, IUD users in the USA increased from $6 \%$ to $12 \%$. Although in Egypt the IUD has been the most common contraceptive method since 1988 , its use has recently decreased from
$36 \%$ to $30 \%$ (Kavanaugh and Jerman, 2018).

Studies of IUD use implemented and monitored by Family Health International in 80 centers located in 33 countries found the incidence of IUD insertion failures to be between 2.3 and 8.3 per 1000 insertions. However, Dermish et al. (2013) found that among providers with a mean of 14.1 years of experience, the 
insertion failure rate was $19.6 \%$ and $13.6 \%$ in nulliparous and parous women respectively.

According to the latest practice recommendations for contraceptive use by the Centers for Disease Control and Prevention, the potential barriers to IUD use include anticipated insertion pain and health care providers' concerns about difficult insertion. It is, therefore, important to identify effective approaches to ease IUD insertion in order to overcome obstacles hindering IUD use (Bahamondes et al., 2015).

Misoprostol has been used extensively in many obstetric and gynecological procedures for its cervical softening effect, which reduces the force required for cervical dilation by decreasing the total collagen content, increasing collagen solubility and increasing collagenolytic activity in a way similar to that of an inflammatory response (Tang et al., 2011).

Misoprostol, a prostaglandin E1 analogue, is well known for its use as a cervical ripening agent in labor induction. It is also used for cervical ripening prior to transcervical procedures such as hysteroscopy, dilation and curettage, and dilation and evacuation. Misoprostol has also been proposed as an agent to ease IUD insertion and decrease procedure associated pain (Zhuo et al., 2016).

The use of misoprostol prior to IUD insertion varies between practitioners, and the literature regarding its efficacy in facilitating IUD insertion and decreasing pain is inconclusive. Misoprostol dose, route of administration, and timing of administration prior to procedure varies widely among available studies.
Additionally, multiple studies include multiple routes of misoprostol administration (sublingual, oral, rectal, and vaginal) (Scavuzzi et al., 2013).

The main objective of our study was to investigate the possible effect of vaginal administration of misoprostol to insertion of IUCDs in women with previous IUCD insertion failure.

\section{PATIENTS AND METHODS}

This study was a double blind randomized clinical trial conducted at AlHussein hospital from March 2019 to March 2020. One hundred patients were distributed into two equal groups: Group A with previous failed attempt of IUD insertion and would receive misoprostol prior to IUD insertion and Group B with previous failed attempt of IUD insertion and received placebo to IUD insertion.

Inclusion criteria: 20 -35 years old, at the last day of menstruation, after purperium of labor, 2 weeks after abortion and one previous failed attempt if IUCD insertion.

Exclusion criteria: Uterine fibroid with distortion of the cavity, anatomical abnormality with distortion of the cavity, current pelvic inflammatory disease, current purulent cervicitis (Chlamydia or gonorrhea), immediately after septic abortion and uterus size less than $6 \mathrm{~cm}$ and more than $9 \mathrm{~cm}$.

\section{All patients were subjected to:}

i. History: Complete history taking: In history taking, age, residency, occupation, Parity, gravidity, previous abortion, previous pregnancy outcomes, presence of comorbidities, such as hypertension were evaluate. 
ii. Clinical examination: General examination: Blood pressure, pulse and temperature. Local examination: abdominal and pelvic examinations.

\section{iii. Interventions:}

- Women who came to the clinic with insertion failure at the first attempt and request an insertion of aTCu380A IUCD again were eligible to participate. IUCD insertion was considered a failure if it was not possible to pass the internal cervical Os with the uterine sound, metallic dilator number 3 and Os finder, which was a tapered plastic dilator with a $1.75 \mathrm{~mm}$ tip to $3.8 \mathrm{~mm}$ outer diameter.

- The invited women signed an informed consent form. The women were instructed to insert vaginally one tablet of misoprostol $200 \mathrm{mg}$ or placebo 10 and $4 \mathrm{~h}$ after soaking in $5 \mathrm{ml}$ saline before the women returning to the clinic for the second attempt of insertion.

- Ultrasound (US) was done before insertion to detect uterine position (anteverted or retroverted) and any intracavitary pathology (uterine anomaly and fibroid uterus). Sterile sanitation by a bimanual examination and sounding of the uterus has been used to determine the uterine position and the depth of the uterine cavity and exclude pelvic mass. Then loading of the IUD was done, which was inserted gently inside the uterus through the cervical canal. Examination was done by US to ensure the position of IUD after application.

- A copper T 380A (Pregna International, Mumbai, India) was inserted on the 5th or 6th day of the menstrual cycle. The cervix was first exposed and cleaned with a povidoneiodine solution. After sounding of the uterus, the IUD was folded into the insertion tube. A tenaculum was used to gently straighten the angle of the uterus before insertion of the IUD. The strings were then cut to project about 2 $\mathrm{cm}$ from the external cervical os. This technique was used in all participants without the aid of ultrasound guidance or cervical dilation.

- In case of failure of IUD insertion, a second trial of IUD application was done during the next menstruation.

\section{Ethical committee:}

Permission from the Faculty of Medicine ethical committee was also obtained and approval from institutional review board was taken. The title and objectives of the study were explained to them to ensure their cooperation.

\section{Statistical analysis:}

Analysis of data was done using Statistical Package for the Social Science version 22 (SPSS Inc., Chicago, IL, USA). Quantitative variables were described in the form of mean and standard deviation. Qualitative variables were described as number and percent. In order to compare parametric quantitative variables between two groups, Student t test was performed. Qualitative variables were compared using chi-square (X2) test or Fisher's exact test when frequencies were below five. $\mathrm{P}$ value $<0.05$ is considered significant. 


\section{RESULTS}

There was no statistically significant difference between groups according to age or weight, and highly statistically significant difference between groups according to success of insertion (Table 1).

Table (1): Comparison between groups according to baseline data and success of insertion

\begin{tabular}{|c|c|c|c|c|c|}
\hline $\begin{array}{ll}\text { Parameters } & \text { Groups } \\
\end{array}$ & \multicolumn{2}{|c|}{$\begin{array}{c}\text { Group A } \\
\mathbf{N}=\mathbf{5 0}\end{array}$} & \multicolumn{2}{|c|}{$\begin{array}{c}\text { Group B } \\
\mathbf{N}=\mathbf{5 0}\end{array}$} & p-value \\
\hline $\begin{array}{c}\text { Age (years) } \\
\text { Mean } \pm \text { SD } \\
\text { Range }\end{array}$ & \multicolumn{2}{|c|}{$\begin{array}{l}30.13 \pm 5.61 \\
20-42\end{array}$} & \multicolumn{2}{|c|}{$\begin{array}{c}30.10 \pm 6.11 \\
19-42\end{array}$} & 0.98 \\
\hline $\begin{array}{l}\text { Weight }(\mathbf{k g}) \\
\text { Mean } \pm \text { SD } \\
\text { Range }\end{array}$ & \multicolumn{2}{|c|}{$\begin{array}{c}86.92 \pm 12.13 \\
66-117 \\
\end{array}$} & \multicolumn{2}{|c|}{$\begin{array}{c}86.11 \pm 11.19 \\
55-115\end{array}$} & 0.73 \\
\hline Success of introduction: & No. & $\%$ & No. & $\%$ & \multirow{4}{*}{$<0.001$} \\
\hline Negative & 6 & 12.0 & 25 & 50.0 & \\
\hline Positive & 44 & 88.0 & 25 & 50.0 & \\
\hline Total & 50 & 100.0 & 50 & 100.0 & \\
\hline
\end{tabular}

Misoprostol increased the success rate from $60.6 \%$ to $91.4 \%$ in group with previous cesarean section, and from 29.4 $\%$ to $80 \%$ in the group with previous vaginal delivery with a $\mathrm{P}$ value 0.037 . There was no significant difference between the two groups according to the timing of IUCD insertion. Also there was a high significant effect of the timing of insertion whether it was postmenstrual or post-delivery and post abortion (Table 2).

Table (2): Comparison between groups according to the mode of previous deliveries, timing and its effect on the successful rate of IUCD insertion in each group

\begin{tabular}{|c|c|c|c|c|c|}
\hline \multirow{2}{*}{ Parameters } & \multicolumn{2}{|c|}{$\begin{array}{c}\text { Group (A) Success of } \\
\text { introduction }\end{array}$} & \multicolumn{2}{|c|}{$\begin{array}{c}\text { Group (B) Success of } \\
\text { introduction }\end{array}$} & \multirow{3}{*}{ p-value } \\
\hline & Positive & Negative & Positive & Negative & \\
\hline \multicolumn{5}{|c|}{ Mode of Delivery: } & \\
\hline CS & $\begin{array}{c}32 \\
(91.4 \%)\end{array}$ & $\begin{array}{c}3 \\
(8.6 \%)\end{array}$ & $\begin{array}{c}20 \\
(60.6 \%)\end{array}$ & $\begin{array}{c}13 \\
(39.4 \%)\end{array}$ & 0.003 \\
\hline VD & $\begin{array}{c}12 \\
(80.0 \%)\end{array}$ & $\begin{array}{c}3 \\
(20.0 \%)\end{array}$ & $5(29.4 \%)$ & $\begin{array}{c}12 \\
(70.6 \%)\end{array}$ & 0.004 \\
\hline \multicolumn{6}{|c|}{ Timing of IUCD insertion: } \\
\hline \multirow{2}{*}{$\begin{array}{l}\text { Postmenstural } \\
\text { insertion }\end{array}$} & 26 & 3 & 20 & 7 & \multirow{2}{*}{0.13} \\
\hline & $89.7 \%$ & $10.3 \%$ & 74.1 & 25.1 & \\
\hline \multirow{2}{*}{$\begin{array}{l}\text { Post-delivery and } \\
\text { post abortion }\end{array}$} & 18 & 3 & 5 & 18 & \multirow[t]{2}{*}{0.001} \\
\hline & $85.7 \%$ & $14.3 \%$ & $21.7 \%$ & $78.3 \%$ & \\
\hline
\end{tabular}


This table shows a significant difference between the two groups regarding the need to cervical dilatation on the successful rate of insertion. This table shows a high significant difference between the two groups regarding the degree of cervical softening and its effect on the success rate of IUCD insertion in each group (Table 3).

Table (3): Comparison between groups according to the need to cervical dilatation, degree of cervical softening and its effect on the successful rate of IUCD insertion in each group

\begin{tabular}{|c|c|c|c|c|c|}
\hline \multirow{2}{*}{ Groups } & \multicolumn{2}{|c|}{$\begin{array}{l}\text { Group (A) Success of } \\
\text { introduction }\end{array}$} & \multicolumn{2}{|c|}{$\begin{array}{l}\text { Group (B) Success of } \\
\text { introduction }\end{array}$} & \multirow[t]{2}{*}{ p-value } \\
\hline & Positive & Negative & Positive & Negative & \\
\hline \multicolumn{6}{|c|}{ Need to dilation: } \\
\hline Negative & $25(100 \%)$ & $0(0 \%)$ & $1(50.0 \%)$ & $1(50.0 \%)$ & $\begin{array}{c}<0.001 \\
(\mathbf{H S})\end{array}$ \\
\hline Positive & $\begin{array}{c}19 \\
(87.5 \%)\end{array}$ & $\begin{array}{c}6 \\
(12.5 \%)\end{array}$ & $\begin{array}{c}24 \\
(50.0 \%)\end{array}$ & $\begin{array}{c}24 \\
(50.0 \%)\end{array}$ & 0.032 \\
\hline \multicolumn{6}{|c|}{ Degree of softening: } \\
\hline Firm & $8(80.0 \%)$ & $2(20.0 \%)$ & $1(100.0 \%)$ & $0(0 \%)$ & \multirow{3}{*}{$<0.001$} \\
\hline Hard & $2(40.0 \%)$ & $3(60.0 \%)$ & $23(47.9 \%)$ & $25(52.1 \%)$ & \\
\hline Soft & $34(97.1 \%)$ & $1(2.9 \%)$ & $1(100 \%)$ & $\mathbf{0}(\mathbf{0 \%})$ & \\
\hline
\end{tabular}

\section{DISCUSSION}

There was no statistically significant difference between groups according to age, weight or parity. Our results were in agreement with study of Abdellah et al. (2017) as they reported that there were no significant differences in baseline characteristics that were found between the two groups. According to Maged et al. (2018) there were no significant differences in baseline characteristics between the two study groups.

In many studies, misoprostol, administered before the insertion of an IUC was used with the aim of priming the internal cervical os in order to improve the ease of insertion or to reduce the rate of insertion failure (Heikinheimo et al., 2010).

As regard success of insertion, the present study shows that there was highly statistically significant difference between groups according to success of insertion.

Our results were in line with study of Bahamondes et al. (2015) as they showed that misoprostol was significantly better than placebo at facilitating the insertion of an IUC after insertion failed at the first attempt although the use of cervical dilators was similar among both groups.

Our results were in the opposite direction with some studies that found that misoprostol was not useful to facilitate the insertion of IUCs. However, most of these previous studies have been carried out with unselected women whereas in the present study women were selected among those with previous insertion failure (Lathrop et al., 2013 and Espey et al., 2014).

Grimes et al. (2011) compared oral diclofenac $100 \mathrm{mg}$ alone with sublingual misoprostol $400 \mathrm{mcg}+$ diclofenac $100 \mathrm{mg}$ 
$1 \mathrm{~h}$ before the procedure in patients who had no history of vaginal deliveries and desired copper IUD. Two insertion attempts failed in the control group versus none in the misoprostol group. Pain during insertion was measured using a 10point VAS and was similar in both groups. Also results of this study were similar to their study as no difference was found regarding pain reduction in misoprostol group.

The current study showed that there was no statistically significant difference between groups according to the mode of previous deliveries. Misoprostol increased the success rate from $60.6 \%$ to $91.4 \%$ in group with previous cesarean section, and from $29.4 \%$ to $80 \%$ in the group with previous vaginal delivery.

Our results are supported by study of Bahamondes et al. (2011) who reported that history of prior $\mathrm{CD}$ is not a contraindication or obstacle for IUD insertion.

Abdellah et al. (2017) found that the ES (the ease of insertion score) reported by the physician after the insertion was lower in the misoprostol group with a higher number of successful IUD insertions more than the placebo group. The mean difference in pain score reported by the women was lower in misoprostol group with a higher level of satisfaction from the whole procedure.

Maged et al. (2018) demonstrated that pain and insertion difficulty scores were significantly lower in the misoprostol group compared with the placebo group.

The present study showed that there was no significant difference between the two groups according to the timing of
IUCD insertion. Also, it showed that there was a high significant effect of the timing of insertion whether it was postmenstrual or post-delivery and post abortion. There was no statistically significant difference between the groups according to the position of the uterus and uterine length measured by uterine sounding.

Our results were in line with study of Maged et al. (2018) as they reported that there was no statistically significant difference between the groups according to the position of the uterus. Bahamondes et al. (2015) found that there was no statistically significant difference between the groups according to the position of the uterus and the uterine length.

The current study showed that there was a statistically significant difference between groups according to the need to cervical dilation, softening and the success rate of IUCD insertion in each group.

Our results were supported by study of Rasheedy et al. (2019) as they reported that a soft cervix was significantly associated with insertion success.

Dijkhuizen et al. (2011) reported that the use of self-administered misoprostol for cervical ripening before insertion of an IUD does not improve ease of insertion for the provider or decrease reported pain for the patient. Scavuzzi et al. (2013) reported that the use of misoprostol at a dose of $400 \mu \mathrm{g}$ administered vaginally $1 \mathrm{~h}$ before IUD insertion increased the ease of insertion and reduced the incidence of pain during the procedure.

\section{CONCLUSION}

Vaginal misoprostol before IUD insertion in parous women with previous insertion failure increased the rate of 
successful insertion, particularly in women with previous cesarean delivery.

\section{REFERENCES}

1. Abdellah MS, Abbas AM, Hegazy AM and EINashar IM. (2017): Vaginal misoprostol prior to intrauterine device insertion in women delivered only by elective cesarean section: a randomized double-blind clinical trial. Contraception, 95(6):538-543.

2. Bahamondes MV, Espejo-Arce $X$ and Bahamondes L. (2015): Effect of vaginal administration of misoprostol before intrauterine contraceptive insertion following previous insertion failure: a double blind RCT. Hum Reprod., 30: 1861-1866.

3. Bahamondes MV, Hidalgo MM, Bahamondes L and Monteiro I. (2011): Ease of insertion and clinical performance of the levonorgestrel-releasing intrauterine system in nulligravidas. Contraception, 84:11-16.

4. Dermish AI, Turok DK and Jacobson JC. (2013): Failed IUD insertions in community practice: an under-recognized problem? Contraception, 87:182-186.

5. Dijkhuizen K, Dekkers OM, Holleboom CA, de Groot CJ, Hellebrekers BW and van Roosmalen GJ. (2011): Vaginal misoprostol prior to insertion of an intrauterine device: an RCT. Human Reprod., 26:323-329.

6. Espey E, Singh RH, Leeman L, Ogburn T, Fowler K and Greene H. (2014): Misoprostol for intrauterine device insertion in nulliparous women: a randomized controlled trial. Am J Obstet Gynecol., 208: 1-5.

7. Grimes DA, Lopez LM, Manion C and Schulz KF. (2011): Cochrane systematic reviews of IUD trials: lessons learned. Contraception, 75: 55-59.

8. Heikinheimo O, Inki P, Kunz M, Parmhed S, Anttila AM, Olsson SE, Hurskainen R and Gemzell-Danielsson K. (2010): Doubleblind, randomized, placebocontrolled study on the effect of misoprostol on ease of consecutive insertion of the levonorgestrelreleasing intrauterine system. Contraception, 81:481486.

9. Kavanaugh ML and Jerman J. (2018): Contraceptive method use in the United States: trends and characteristics between 2008, 2012 and 2014. Contraception, 97:14-21.

10. Lathrop E, Haddad L, McWhorter CP and Goedken P. (2013): Self-administration of misoprostol prior to intrauterine device insertion among nulliparous women: a randomized controlled trial. Contraception, 88:725-729.

11. Maged AM, Youssef G, Eldaly A, Omran E, El Naggar M, Abdel Hak A and Ogila AI. (2018): Benefits of vaginal misoprostol prior to IUD insertion in women with previous caesarean delivery: a randomised controlled trial. The European Journal of Contraception \& Reproductive Health Care, 23(1): 32- 37.

12. Rasheedy R, Tamara TF, Allam IS, Abbas AM, Essam El-Din Abd El Salam $\mathbf{N}$ and Ferhad AA. (2019): Vaginal misoprostol before copper IUD insertion after previous insertion failure: a double-blind, placebocontrolled, parallelgroup, randomised clinical trial. The European Journal of Contraception \& Reproductive Health Care, 24(3): 222-226.

13. Scavuzzi A, Souza ASR, Costa AAR and Amorim MMR (2013): Misoprostol prior to inserting an intrauterine device in multigravidas: A randomized clinical trial. Hum Reprods., 28: 21182125.

14. Tang OS, Gemzell-Danielsson $K$ and Ho PC. (2011): Misoprostol: pharmacokinetic profiles, effects on the uterus and side-effects. Int $\mathbf{J}$ Gynaecol Obstet., 99:S160-S167.

15.Zhuo Z, Yu $H$ and Jiang $X$ (2016): $A$ systematic review and meta-analysis of randomized controlled trials on the effectiveness of cervical ripening with misoprostol administration before hysteroscopy. Int J Gynaecol Obstet., 132: 272277. 


\section{استعمال عقار الميزوبرستول مهبليا قبل تركيب اللولب الرحمى فى النساء اللاتى فنثل التركيب فيهن: در اسة سريرية عشو ائبة}

عمرو محمد السيد، مفيد فوزي محمد، سمير خميس جلال

\section{قسم أمراض النساء و الولادة، كلية طب الأزهر}

E-mail: $\underline{\text { amr_elsayed55@gmail.com }}$

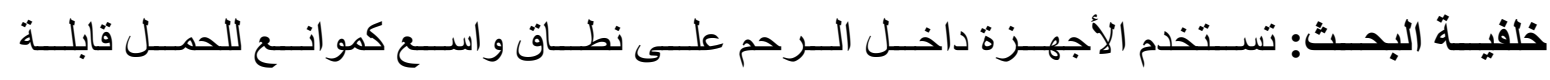

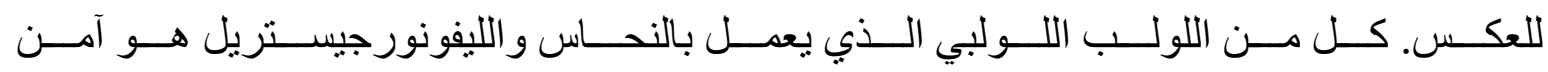

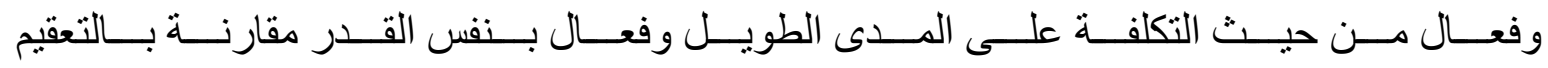

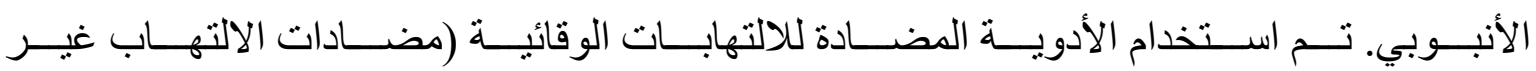

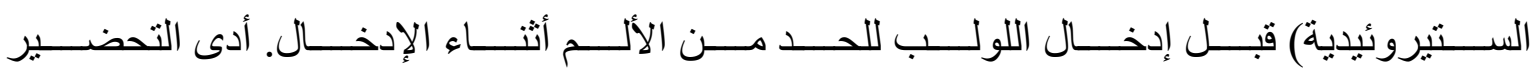

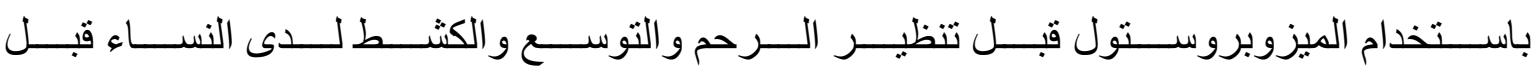
انقطاع الطمث إلى زيادة توسع عنق الرحم و انخفاض معدل تمزق عنق الرحم.

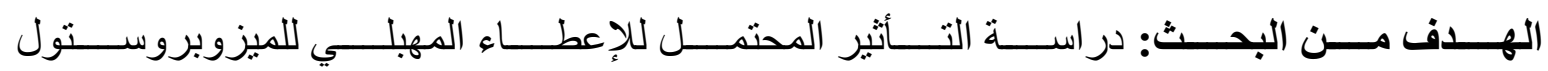

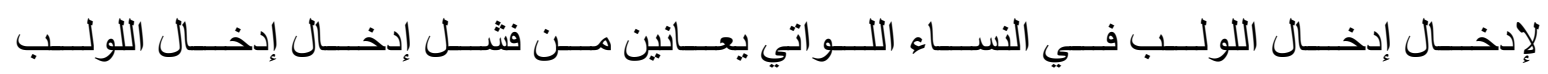

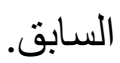

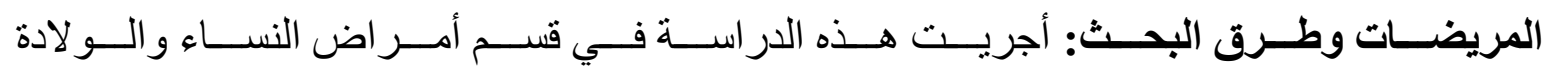

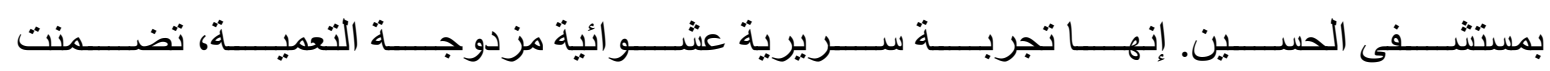

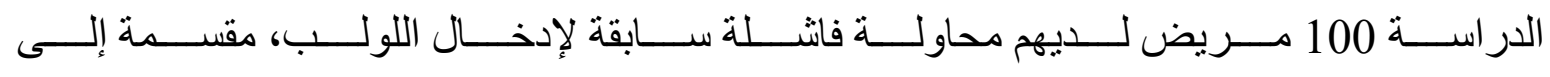

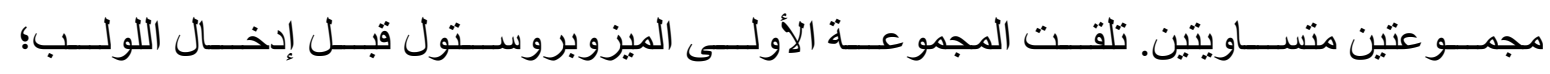
تلقت المجموعة الثانية وهمي لإدخال اللولب.

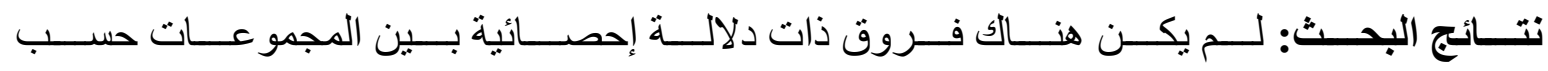

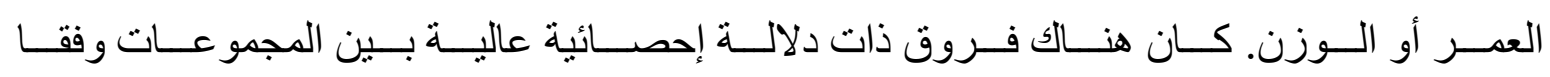

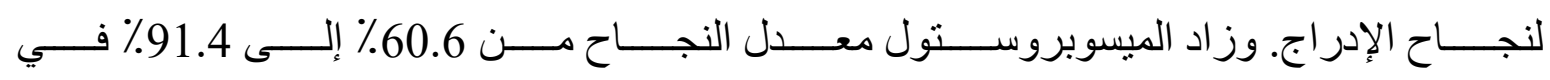

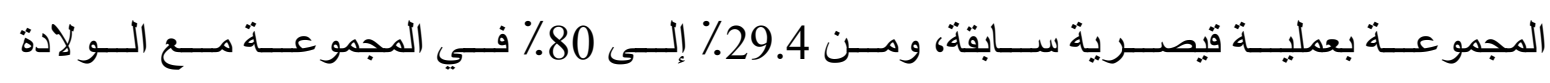

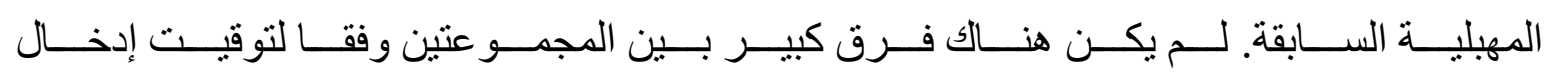




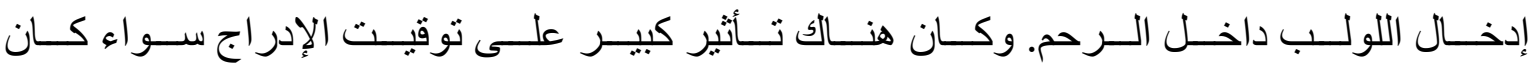

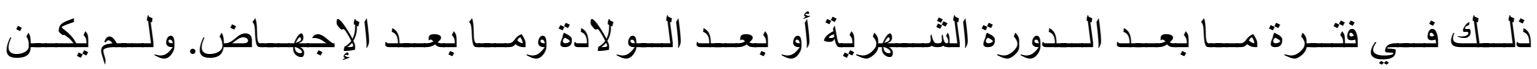

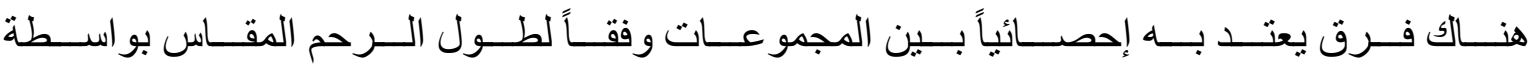

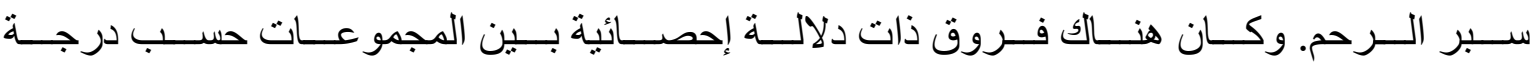

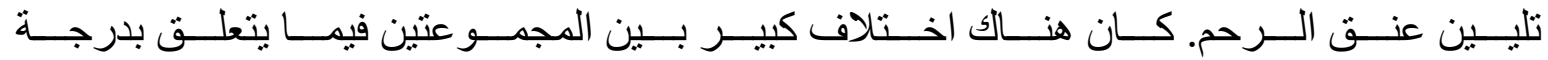

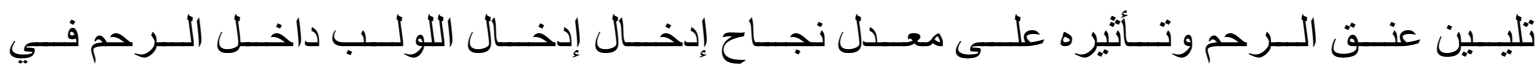

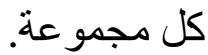

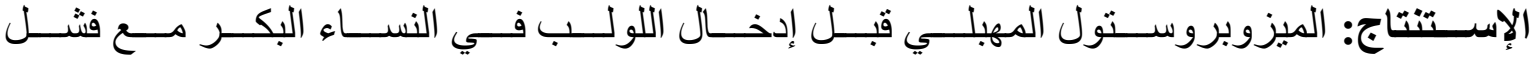

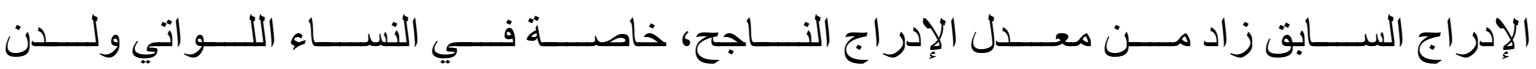

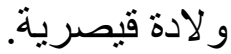
الكلمات الدالة : ميزوبرستول - فنشل التركيب - اللولم الرحمى 